\title{
Effects of Glucagon-like Peptide-1 Analogues and Dipeptidyl Peptidase-IV Inhibitors on Hepatic Oxidative Stress and Non-Alcoholic Steatohepatitis in Male Albino Rats
}

\author{
Osama Mahmoud Mehanna ${ }^{1, *}$, Ahmad Abd Elhakam El Askary², Basem Hasan El Esawy ${ }^{3}$, Tarek Mohamed Ali ${ }^{4}$, \\ Osama Mohamed Abo-Salem ${ }^{5}$
}

\section{Osama Mahmoud Mehanna ${ }^{1, *}$, Ahmad Abd Elhakam El Askary², Basem Hasan El Esawy ${ }^{3}$, Tarek Mohamed $\mathrm{Ali}^{4}$, Osama Mohamed Abo-Salem ${ }^{5}$} Medicine, Taif University, KSA and Department of Physiology, Damietta Faculty of Medicine, Al-Azhar University, EGYPT.

${ }^{2}$ Department of Clinical Laboratory Sciences, College of Applied Medical Sciences, Taif University, KSA and Department of Medical Biochemistry, Damietta Faculty of Medicine, Al-Azhar University, EGYPT

${ }^{3}$ Department of Clinical Laboratory Sciences, College of Applied Medical Sciences, Taif University, KSA and Department of Pathology, Mansoura University, EGYPT.

${ }^{4}$ Department of Medical Physiology, College of Medicine, Taif University, KSA and Department of Medical Physiology, Faculty of Medicine, Beni-Suef University, EGYPT.

${ }^{5}$ Department of Pharmacology and Toxicology, Faculty of Pharmacy (Boys), Al-Azhar University, Nasr City, Cairo, EGYPT.

\section{*Correspondence}

Prof. Osama Mahmoud Mehanna ${ }^{1}$ Assistant Professor, Department of Physiology, Faculty of Medicine, Taif University, KSA and Department of Physiology, Damietta Faculty of Medicine, Al-Azhar University, EGYPT.

Phone: +966 544319549

Email: o.mehanna@tu.edu.sa

\section{History}

- Submission Date: 05-01-2020

- Review completed: 19-02-2020.

- Accepted Date: 18-03-2020

DOI : 10.5530/ijcep.2020.7.1.7

Article Available online

http://www.ijcep.org

Copyright

(c) 2020 Phcog.Net. This is an openaccess article distributed under the terms of the Creative Commons Attribution 4.0 International license.

\begin{abstract}
Background and Aim: Due to their importance in glucose metabolism and lipid accumulation in addition to their prolonged action, overall safety and efficacy; glucagon-like peptide-1 receptor agonists (GLP-1 RAs) and dipeptidyl peptidase-IV inhibitors (DPP-IV inhibitors) are becoming one of the cornerstones for treatment of obesity, T2DM and NASH. This study aimed to distinguish between the effect of both Liraglutide (a long-acting GLP-1 analog) and Sitagliptin (a DPP-IV inhibitor) on nutritional steatohepatitis in adult male rats. Methods: A total of 40 male Sprague-Dawley rats were divided into four groups; the normal control group and the steatohepatitis placebo group; steatohepatitis liraglutide- treated and steatohepatitis sitagliptin-treated groups. Liver weight and functions, lipid profile, glycemic status, hepatic oxidant-antioxidant parameters and histopathological analysis were assessed in comparison with the control rats. Results: Treatment of steatohepatitis in rats with either liraglutide or sitagliptin significantly reduced the levels of blood sugar, insulin, HOMA-IR, hepatic MDA and nitric oxide (NO). Moreover, they significantly increased the antioxidant enzyme activities, improved the histopathological changes compared to the control rats, with slightly superior effects for Liraglutide. Conclusion: Treatment with either GLP-1 RAs or DPP-IV inhibitors improved the hepatocyte viability. Treatment improved the hepatic fatty deposition, attenuated the progression of hepatic fibrosis and reduced the hepatic oxidative stress in male steatohepatitis rats, with slightly superior effects for GLP-1 RAs.

Key words: GLP-1 analogues, DPP-IV Inhibitors, Hepatic Oxidative Stress, NASH,
\end{abstract} Liver function.

\section{INTRODUCTION}

Non-alcoholic steatohepatitis (NASH), although it is one of the most important liver diseases worldwide, there is no available effective treatment. Also, its pathogenesis is not fully understood. ${ }^{[1]}$ Glucagon-like peptide-1 (GLP-1) is a gastrointestinal incretin peptide found initially to improve glucose homeostasis. It seems that GLP-1 affects glucose metabolism via stimulation of insulin synthesis and secretion in a glucose-dependent manner, repression of postprandial glucagon secretion and delaying stomach emptying. ${ }^{[2]}$ Enteroendocrine L-cells in the small intestine (duodenum, distal ileum and colon) synthesize GLP-1 from proglucagon in the in response to oral nutrient ingestion. ${ }^{[3]}$ Once in circulation, it is rapidly degraded by endogenous ubiquitous enzyme dipeptidyl peptidase-IV (DPP-IV), this makes its half-life too short (1 to $2 \mathrm{~min}){ }^{[4]}$ That's why, GLP-1 receptor agonists such as (exenatide, liraglutide, CJC-1131, CJC-1134 and albugon) with increased resistance to dipeptidyl peptidase-IV, or DPP-IV inhibitors such as (sitagliptin, saxagliptin, vildagliptin, alogliptin and linagliptin) have been used in human and

animal studies to overcome this obstacle. ${ }^{[5]}$ Recent studies have shown an effect of GLP-1 on glucose metabolism and lipid accumulation, along with its overall safety and efficacy, all of which make GLP-1, one of the critical pillars of the treatment of NASH associated type 2 diabetes and obesity. ${ }^{[6]}$ The present study aimed to compare the therapeutic effects of Liraglutide "Victoza" (a long-acting GLP-1 analog) and Sitagliptin "Januvia" (a DPP-IV inhibitor) on nutritional steatohepatitis in adult male rats.

\section{MATERIALS AND METHODS}

The ethics committee of Taif University, Saudi Arabia, approved this study. Liraglutide, Sitagliptin and enzymes were purchased from Novo Nordisk (Mill Rd, Princeton, NJ). Other chemicals were obtained from the purest grade available.

\section{Animals}

Forty adult male Sprague-Dawley rats (age, 9-11 weeks; body weight, 100-150 g) were obtained from Nile Pharmaceuticals Co (Cairo, Egypt). Animals were

Cite this article: Mehanna OM, Askary AAEE, Esawy BHE, Ali TM, Abo-Salem OM. Effects of Glucagon-like Peptide-1 Analogues and Dipeptidyl Peptidase-IV Inhibitors on Hepatic Oxidative Stress and Non-Alcoholic Steatohepatitis in Male Albino Rats. Int J Clin Exp Physiol. 2020;7(1):2732. 
treated following the Guide for the Care and Use of Laboratory Animals ( $8^{\text {th }}$ edition, National Academies Press). The animals were acclimatized for two weeks before inclusion in the experiment.

\section{Experimental Design}

\section{Induction of non-alcoholic steatohepatitis (NASH)}

After acclimatization, thirty rats were exposed to a high-fat diet (HFD) (D12451, Research Diets, NJ) containing 45\% fat (kcal \%), 35\% carbohydrate and $20 \%$ protein for four weeks to develop NASH that was confirmed by liver biopsy. ${ }^{[7]}$ Rats had higher liver enzymes, blood sugar, insulin, HOMA-IR, total cholesterol, LDL and triglycerides than the normal control rats.

\section{Grouping}

After induction of NASH, rats were randomly divided into four equal groups $(n=10)$ treated as follows: normal control group (NG); administered water; steatohepatitis placebo-treated group (SPG); steatohepatitis liraglutide-treated group (SLG); treated with freshly prepared liraglutide, given by subcutaneous injection at a dose of $200 \mu \mathrm{g} / \mathrm{kg} / \mathrm{day},{ }^{[8]}$ and steatohepatitis sitagliptin-treated group (SSG); treated with freshly prepared sitagliptin given by gastric tube at a dose of $2 \mathrm{mg} / \mathrm{kg} /$ day as a bolus every afternoon. ${ }^{[9]}$ Animals were treated for 12 weeks.

\section{Biochemical Analysis}

The next day after treatment, blood samples were obtained from the rat tail veins and immediately separated via centrifugation at $2000 \mathrm{rpm}$ for $15 \mathrm{~min}$ at $4^{\circ} \mathrm{C}$ and were stored at $-80^{\circ} \mathrm{C}$ until further use. The separated serum was used for the determination of fasting and postprandial blood sugar, insulin, insulin resistance index (HOMA-IR), liver enzymes, alkaline phosphatase and lipid profile.

\section{Evaluation of Oxidative Stress}

Reduced glutathione (GSH) was assessed by treating $0.5 \mathrm{~mL}$ of the supernatant with $0.5 \mathrm{~mL}$ Ellman's reagent $(19.8 \mathrm{mg}$ of 5,5_- dithio-2nitrobenzoic benzoic acid in $100 \mathrm{~mL}$ of $0.1 \%$ sodium nitrate) and $3 \mathrm{~mL}$ of phosphate buffer $(0.2 \mathrm{M}, \mathrm{pH} 8) .^{[10]}$ Ellman's reagent was reduced by -SH group of (GSH) to form 5,5-dithio-2-nitrobenzoic acid in phosphate buffer producing a yellow color, which was read at $412 \mathrm{~nm} \cdot{ }^{[11]}$ Lipid peroxide was determined colorimetrically by determining the tissue MDA content in the form of thiobarbituric acid reactive substances using 1,1_,3,3_-tetramethoxypropane as a standard. ${ }^{[12]}$ Catalase (CAT) activity in the supernatant was measured spectrophotometrically by adding $50 \mu \mathrm{l}$ of the supernatant to $2.95 \mathrm{~mL}$ of $19 \mathrm{mM} \mathrm{H}_{2} \mathrm{O}_{2}$ solution (in $50 \mathrm{mM}$ potassium phosphate buffer $\mathrm{pH}$ 7.05). The changes in the absorbance at $240 \mathrm{~nm}$ were monitored spectrophotometrically over 5 min periods. Each unit of CAT activity represents the amount of CAT required to decompose $1 \mu \mathrm{mol}$ of $\mathrm{H}_{2} \mathrm{O}_{2} / \mathrm{min}$ at $\mathrm{pH}$ seven at $25^{\circ} \mathrm{C}$. ${ }^{[11]}$ The activity of superoxide dismutase (SOD) was determined by assessing the inhibition of pyrogallol autooxidation. The changes in the absorbance were recorded at $420 \mathrm{~nm}$ for $5 \mathrm{~min}$ at a 1 -min interval. ${ }^{[12]}$ Glutathione peroxidase (GPx) activity was assessed using a Glutathione Peroxidase Assay Kit (ab102530; Abcam) and the results were expressed as units/mg protein. ${ }^{[13]}$ For measurement of the plasma total antioxidant capacity (TAC), a TAC kit (Abcam, Cambridge, UK) was used, where the plasma was allowed to reduce $\mathrm{Cu}^{2+} \hat{\mathrm{A}}$ at room temperature for $1.5 \mathrm{hr}$ according to the manufacturer's instructions. With a colorimetric probe, the reduced $\mathrm{Cu}^{+} \hat{\mathrm{A}}$ was chelated and the absorbance was measured at $570 \mathrm{~nm}$. According to a Trolox standard curve, the results were expressed as Trolox equivalent.

\section{Histopathological Study}

After the collection of blood samples, the animals of different groups were sacrificed under light anesthesia (diethyl ether). A small piece of hepatic tissue was removed for histological analysis. The sample was fixed by immersing it in 10\% neutral-buffered formalin. The sample was then embedded in paraffin, sliced into $5 \mu \mathrm{m}$ sections and stained with hematoxylin-eosin and Masson's trichrome stain for histological assessment. The degree of liver tissue injury was evaluated. The stained $5 \mu \mathrm{m}$ sections were graded as follows: 0 , absent; 1 , minimal; 2 , mild; 3, modest; 4, severe. ${ }^{[14]}$ The histological changes were evaluated in nonconsecutive, randomly chosen $\times 100,200$ and 400 histological fields using a light microscope, Nikon Eclipse E200.

\section{Statistical Analysis}

The results were analyzed for statistical significance by Statistical Package in Social Science (SPSS) version 16.0 for Windows (SPSS Inc., Chicago, USA). All data were expressed as mean \pm SEM of 10 animals in each group. A value of $P \leq 0.05$ was considered statistically significant.

\section{RESULTS}

\section{Effect of Treatment on Liver Weight and Liver Function}

Table 1 revealed that the placebo-treated steatohepatitis rats had significantly $(P<0.05)$ higher liver weight as compared with the normal control rats. However, treatment of steatohepatitis rats with liraglutide or sitagliptin revealed a significant $(P<0.05)$ decrease in liver weight when compared with the placebo-treated steatohepatitis rats. Regarding the liver functions, Table 1 also showed a significant $(P<0.05)$ increase in the serum levels of AST, ALT and ALP in placebo-treated steatohepatitis rats when compared with the normal control rats. Whereas treatment with either liraglutide or sitagliptin significantly $(P<0.05)$ reduced the AST, ALT and ALP levels compared with the placebo-treated steatohepatitis rats.

\section{Effect of Treatment on Glycemic Status and Lipid Profile}

Table 2 revealed that the placebo-treated steatohepatitis rats had significantly $(P<0.05)$ higher levels of FBG and Postprandial BG compared with the normal control rats. Moreover, treatment with liraglutide or sitagliptin significantly $(P<0.05)$ reduced the levels of FBG and Postprandial BG compared with that in placebo-treated steatohepatitis rats. Concerning the insulin level and HOMA-IR, placebo-treated steatohepatitis rats revealed a significant $(P<0.05)$ increase in insulin level and HOMA-IR compared with the normal rats.

Table 1: Effect of treatment on the liver weight and liver function in HFD-Induced steatohepatitic rats.

\begin{tabular}{ccccc} 
Parameters & \multicolumn{4}{c}{ Groups } \\
& NG & SPG & SLG & SSG \\
\hline Liver Weight (g) & $1.88 \pm 18.13$ & $3.33 \pm 67.8^{\mathrm{a}}$ & $2.02 \pm 23.4^{\mathrm{b}}$ & $2.13 \pm 18.6^{\mathrm{b}}$ \\
ALT (IU/L) & $42.17 \pm 16.53$ & $193.4 \pm 61.04^{\mathrm{a}}$ & $72.26 \pm 51^{\mathrm{b}}$ & $87.1 \pm 71.1^{\mathrm{b}}$ \\
AST (IU/L) & $54.28 \pm 0.55$ & $227.9 \pm 0.31^{\mathrm{a}}$ & $86.1 \pm 0.72^{\mathrm{b}}$ & $98.3 \pm 0.48^{\mathrm{b}}$ \\
ALP (IU/L) & $51.92 \pm 0.52$ & $214.9 \pm 0.37^{\mathrm{a}}$ & $90.1 \pm 0.65^{\mathrm{b}}$ & $102.1 \pm 0.68^{\mathrm{b}}$
\end{tabular}

Data are expressed as mean \pm standard error of mean, $n=10$ rats.

NG, normal control; SPG, steatohepatitic placebo-treated group; SLG, steatohepatitic liraglutide-treated group; SSG, steatohepatitic sitagliptin-treated group;

aSignificantly different from NG; ${ }^{b}$ Significantly different from diabetic control group. 
Table 2: Effect of treatment on glycemic status and lipid profile in HFD-Induced steatohepatitic rats.

\begin{tabular}{ccccc} 
Parameters & \multicolumn{4}{c}{ Groups } \\
& NG & SPG & SLG & SSG \\
FBG (mg/dl) & $67.5 \pm 11.3$ & $138.4 \pm 66.2^{\mathrm{a}}$ & $68.9 \pm 60.8^{\mathrm{b}}$ & $73.5 \pm 32.1^{\mathrm{b}}$ \\
$\begin{array}{c}\text { Postprandial BG } \\
(\mathrm{mg} / \mathrm{dl})\end{array}$ & $97.11 \pm 14.3$ & $187 \pm 60.4^{\mathrm{a}}$ & $103 \pm 41.03^{\mathrm{b}}$ & $111.4 \pm 51^{\mathrm{b}}$ \\
$\begin{array}{c}\text { Insulin (ng/dl) } \\
\text { HOMA-IR }\end{array}$ & $2.96 \pm 0.25$ & $6.1 \pm 0.71^{\mathrm{a}}$ & $3.02 \pm 0.41^{\mathrm{b}}$ & $3.76 \pm 0.52^{\mathrm{b}}$ \\
$\begin{array}{c}\text { Total cholesterol } \\
(\mathrm{mmol} / \mathrm{L})\end{array}$ & $93.3 \pm 9.55$ & $148.7 \pm 7.3^{\mathrm{a}}$ & $107.1 \pm 5.8^{\mathrm{b}}$ & $104 \pm 14.2^{\mathrm{b}}$ \\
$\begin{array}{c}\text { HDL-cholesterol } \\
(\mathrm{mmol} / \mathrm{L})\end{array}$ & $50.19 \pm 3.2$ & $27.33 \pm 4.2^{\mathrm{a}}$ & $29.32 \pm 4.9^{\mathrm{a}}$ & $33.98 \pm 6.2^{\mathrm{a}}$ \\
$\begin{array}{c}\text { LDL-cholesterol } \\
(\mathrm{mmol} / \mathrm{L})\end{array}$ & $70.21 \pm 8.6$ & $112 \pm 9.5^{\mathrm{a}}$ & $68.46 \pm 5.3^{\mathrm{b}}$ & $71.08 \pm 6.2^{\mathrm{b}}$ \\
$\begin{array}{c}\text { Triglycerides } \\
(\mathrm{mmol} / \mathrm{L})\end{array}$ & $71.15 \pm 5.3$ & $84.4 \pm 8.8^{\mathrm{a}}$ & $69.5 \pm 5.7^{\mathrm{b}}$ & $65.99 \pm 7.3^{\mathrm{b}}$ \\
\hline & & & &
\end{tabular}

Data are expressed as mean \pm standard error of mean, $n=10$ rats.

NG, normal control; SPG, steatohepatitic placebo-treated group; SLG, steatohepatitic liraglutide-treated group; SSG, steatohepatitic sitagliptin-treated group;

aSignificantly different from NG; 'bignificantly different from diabetic control group.

However, treatment with liraglutide and/or sitagliptin significantly $(P<0.05)$ decreased the insulin level and HOMA-IR compared to that in placebo-treated steatohepatitis rats.

Concerning the lipid profile, Table 2 revealed that the placebo-treated steatohepatitis rats had significantly $(P<0.05)$ higher levels of total cholesterol, LDL-cholesterol and triglycerides compared with the normal control rats. Moreover, their levels were significantly $(P<0.05)$ reduced after treatment with liraglutide and/or sitagliptin as compared with the placebo-treated steatohepatitis rats.

\section{Effect of Treatment on Hepatic Oxidant/Antioxidant Parameters}

Table 3 revealed that the placebo-treated steatohepatitis rats had significantly $(P<0.05)$ higher levels of MDA and NO compared with normal rats. Treatment with liraglutide or sitagliptin significantly $(P<0.05)$ reduced the level of MDA and NO compared with that in placebo-treated steatohepatitis rats. Placebo-treated steatohepatitis rats showed a significantly $(P<0.05)$ lower GSH, GPx, SOD, CAT and TAC levels as compared with normal rats; whereas, such effects were significantly $(P<0.05)$ improved by either drug treatment.

\section{Effect of Treatment on Histopathological Changes}

Microscopic examination of the liver sections of the control animals (NG) showed the normal architecture of hepatic lobules in the form of hepatocytes arranged from the portal vein (Figure 1). Examination of rat livers from the steatohepatitis placebo-treated group showed loss of architecture, hepatocytes ballooning, macro- and microvesicular steatosis, inflammation, apoptotic nuclei, occasional binucleation, cellular inflammatory infiltrate and bridging fibrosis and pericellular/perisinusoidal fibrotic changes (Figure 2-4). These changes were remarkably improved in the steatohepatitis liraglutide-treated group (SLG, Figure 5) than the steatohepatitis sitagliptin-treated group (SSG, Figure 6).
Table 3: Effect of treatment on oxidative stress markers in HFD-Induced steatohepatitic rats.

\begin{tabular}{|c|c|c|c|c|}
\hline \multirow[t]{2}{*}{ Parameters } & \multicolumn{4}{|c|}{ Groups } \\
\hline & NG & SPG & SLG & SSG \\
\hline $\begin{array}{c}\text { MDA } \\
\text { (nmol/mg protein) }\end{array}$ & $1.77 \pm 0.13$ & $4.71 \pm 0.34^{\mathrm{a}}$ & $2.72 \pm 0.41^{\mathrm{b}}$ & $2.91 \pm 0.15^{b}$ \\
\hline $\mathrm{NO}(\mu \mathrm{mol} / \mathrm{L})$ & $4.89 \pm 1.73$ & $21.79 \pm 4.6^{\mathrm{a}}$ & $8.09 \pm 1.11^{\mathrm{b}}$ & $8.76 \pm 2.32^{b}$ \\
\hline $\begin{array}{l}\mathrm{GSH}(\mu \mathrm{g} / \mathrm{mg} \\
\text { protein })\end{array}$ & $7.09 \pm 1.05$ & $3.56 \pm 0.88^{\mathrm{a}}$ & $8.50 \pm 0.72^{\mathrm{b}}$ & $8.31 \pm 1.08^{b}$ \\
\hline $\begin{array}{l}\text { GPx (Units/mg } \\
\text { protein) }\end{array}$ & $28.8 \pm 2.82$ & $18.77 \pm 1.9^{\mathrm{a}}$ & $25.97 \pm 3.08^{b}$ & $26.74 \pm 2.1^{b}$ \\
\hline $\begin{array}{l}\text { SOD (Units/mg } \\
\text { protein) }\end{array}$ & $5.03 \pm 0.43$ & $2.51 \pm 0.75^{\mathrm{a}}$ & $4.38 \pm 1.39^{\mathrm{b}}$ & $4.15 \pm 1.13^{\mathrm{b}}$ \\
\hline $\begin{array}{c}\mathrm{CAT}\left(\mu \mathrm{mol} \mathrm{H}_{2} \mathrm{O}_{2} /\right. \\
\mathrm{min} / \mathrm{mg} \text { protein })\end{array}$ & $7.11 \pm 1.56$ & $3.15 \pm 0.56^{\mathrm{a}}$ & $4.42 \pm 1.07^{\mathrm{b}}$ & $4.48 \pm 1.16^{\mathrm{b}}$ \\
\hline $\begin{array}{c}\text { TAC ( } \mu \text { mol Trolox } \\
\text { Eqv/mg protein) }\end{array}$ & $2.41 \pm 0.22$ & $1.45 \pm 0.46^{\mathrm{a}}$ & $2.27 \pm 0.19^{\mathrm{b}}$ & $2.22 \pm 0.13^{\mathrm{b}}$ \\
\hline
\end{tabular}

Data are expressed as mean \pm standard error of mean, $n=10$ rats.

NG, normal control; SPG, steatohepatitic placebo-treated group; SLG, steatohepatitic liraglutide-treated group; SSG, steatohepatitic sitagliptin-treated group;

aSignificantly different from NG; 'bignificantly different from diabetic control group.

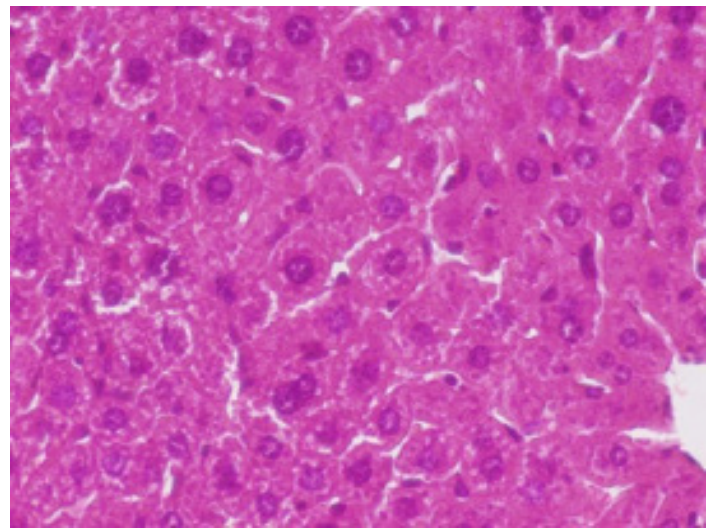

Figure 1: Microscopic examination from the liver tissue of control group showing normal hepatic structure (H\&E, 100x).

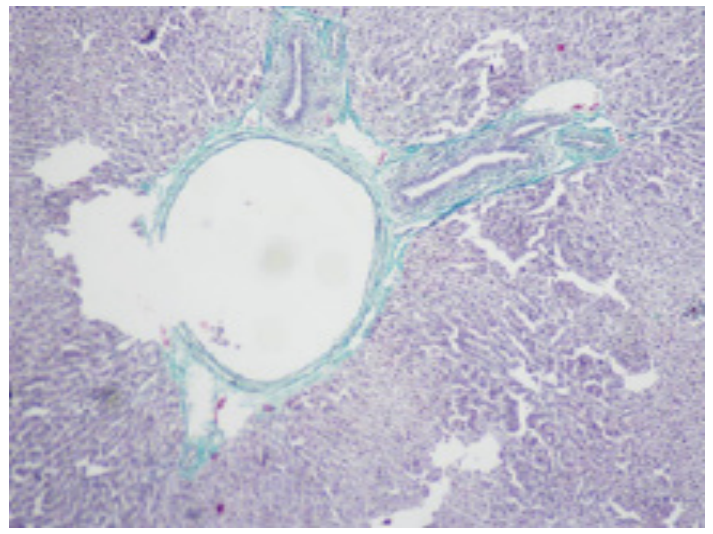

Figure 2: Microscopic examination from the liver tissue of placebo-treated group showing periportal and bridging fibrosis (Masson's trichrome stain, $100 \times)$ 


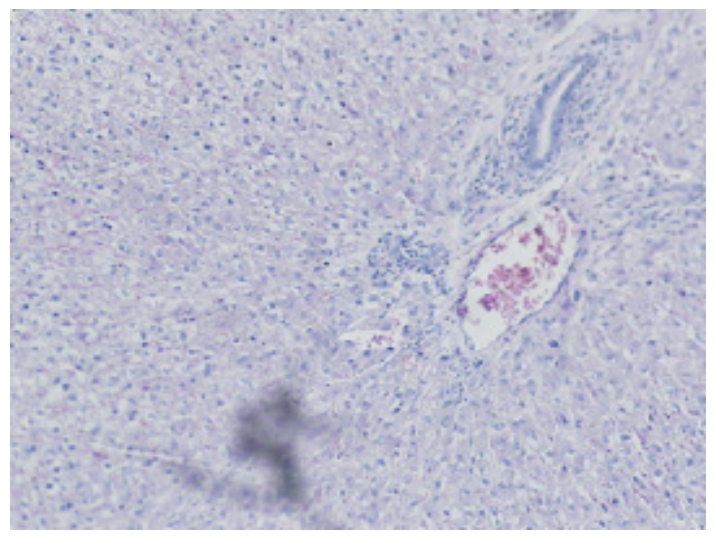

Figure 3: Microscopic examination from the liver tissue of placebo-treated group showing hepatocyte ballooning, steatosis and inflammatory infiltrate (H\&E, 100x).

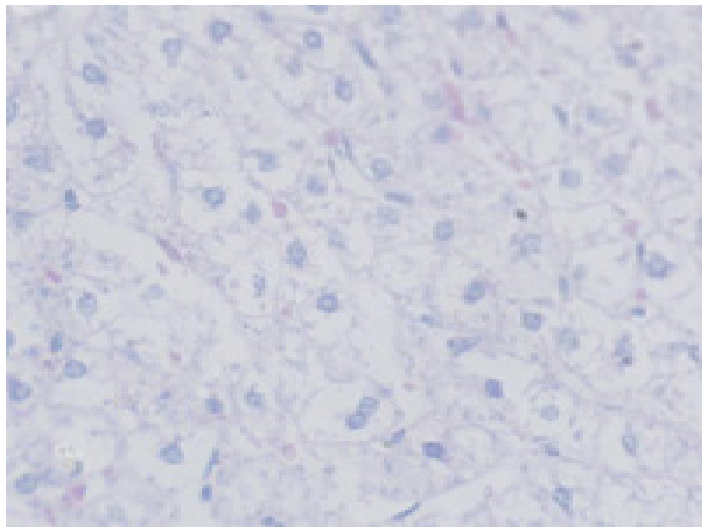

Figure 4: Microscopic examination from the liver tissue of placebo-treated group showing ballooning degeneration and apopotitic bodies in centrilobular portion (H\&E, 400x).

\section{DISCUSSION}

This study compared the therapeutic effects of a long-acting GLP-1 receptor agonist "liraglutide" and a dipeptidyl peptidase-IV inhibitor "sitagliptin," on nutritional steatohepatitis in adult male rats. Results of the present study revealed that the treatment of steatohepatitis rats with liraglutide or sitagliptin improves the steatohepatitis-induced deterioration of liver functions proved by decreasing the liver enzymes, alkaline phosphatase along with diminishing the liver weight. These effects clearly appeared with GLP-1R agonist as it binds to its specific receptors on hepatocytes, ${ }^{[15]}$ and significantly reduces the hepatic fatty acid content, improves the hepatic markers and consequently the hepatocyte viability. ${ }^{[16,17]}$ Recent studies also revealed similar results with sitagliptin which improves the hepatic fatty deposition and inhibits inflammation of hepatocytes in obese male rats. ${ }^{[18,19]}$

Regarding the deteriorated glycemic status secondary to NASH induction in adult male rats, our results revealed a significant reduction of fasting, postprandial BG and insulin resistance after treatment with either liraglutide or sitagliptin. Previous studies revealed similar results with GLP-1R agonists, ${ }^{[20,21]}$ where the authors reported that GLP-1 analogues reduce the blood glucose in obese mice by increasing its hepatic uptake and also by reducing hepatic gluconeogenesis by inhibiting the enzymes (glucose-6-phosphatase and phosphoenolpyruvate carboxykinase). Park et al. ${ }^{[22]}$ also reported that GLP-1R agonists decrease the hepatic glucose output and improve the hepatic insulin signaling in HFD fed diabetic

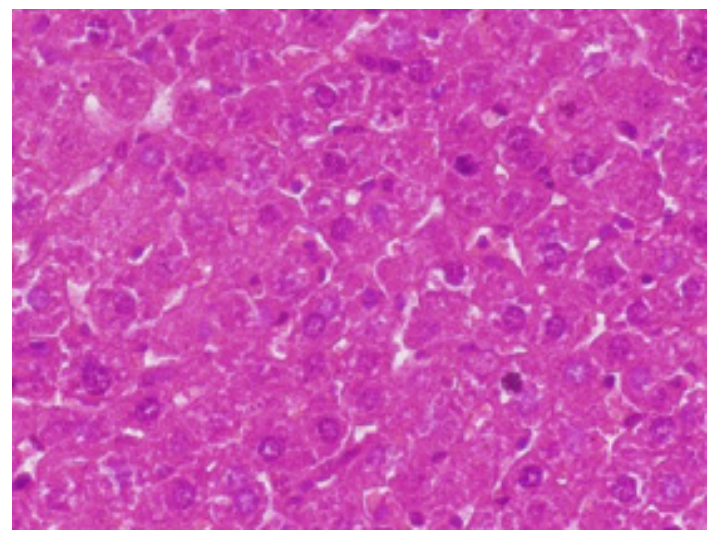

Figure 5: Microscopic examination from the liver tissue of steatohepatitic liraglutide-treated group showing restored liver architecture with near normal hepatocytes (H\&E, 200x).

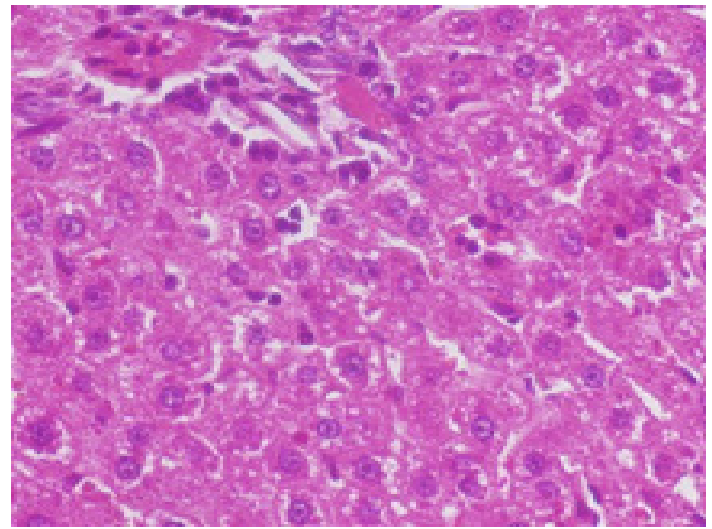

Figure 6: Microscopic examination from the liver tissue of steatohepatitic sitagliptin-treated group showing scattered microvesicular steatosis (H\&E, 200x).

rats via potentiation of tyrosine phosphorylation of the insulin receptor substrate-2. Similar results also recorded for sitagliptin in a study conducted by Tessari et al. ${ }^{[23]}$ who found that sitagliptin attenuates degradation of GLP-1 and consequently increases insulin and reduces blood glucose levels.

Concerning the resulting dyslipidemia (increased total cholesterol, LDL-cholesterol and triglyceride levels and decreased HDL-cholesterol level) after NASH induction, results of our study reveals the effectiveness of treatment with either liraglutide or sitagliptin in improving the lipid profile of steatohepatitis rats proved by significant reduction of the total cholesterol, LDL-cholesterol and triglycerides levels with no significant improvement in HDL-cholesterol level after treatment. Sun et al. ${ }^{[24]}$ have previously recorded such conclusions for liraglutide and Scott et al. ${ }^{[25]}$ and Shirakawa et al. ${ }^{[26]}$ for sitagliptin. The lipid-lowering effect of GLP-1 may be attributed to its ability to reduce the intestinal absorption of dietary lipids, either by deceleration of gastric emptying ${ }^{[27]}$ or inhibition of gastric lipase enzyme and inhibition of lymph flow. ${ }^{[28]}$ Farr et al. ${ }^{[29]}$ reported that GLP-1 possibly produced its lipid-lowering effect via reduction of chylomicrons formation after fatty meals and/or augmentation of hepatic fatty acid oxidation or autophagy. Suppression of lipolysis secondary to increased insulin and decreased glucagon secretion is an additional mechanism for the lipid-lowering effect of GLP-1. ${ }^{[30]}$

Concerning the hepatic antioxidant status, the present study revealed increased tissue concentration of $\mathrm{NO}, \mathrm{MDA}$ and reduction of antioxidant enzymes activities and TAC secondary to NASH induction. Li et al. ${ }^{[31]}$ 
reported that oxidant/antioxidant imbalance greatly disturbs the homeostasis and the resulting oxidative stress enhances liver diseases and other chronic degenerative disorders, including diabetes and its complications, neurological disorders and cancer. After treatment with liraglutide or sitagliptin, our results revealed a significant reduction of $\mathrm{NO}$ and MDA levels and restoration of antioxidant enzymes activities and TAC. A recent study by Allam et al. ${ }^{[32]}$ showed that administration of GLP-1 analogs to steatohepatitis mice restores the oxidant/antioxidant balance, which is necessary for proper liver cell functions and various metabolic processes. Ding et al. ${ }^{[33]}$ also recorded a significant reduction in the oxidative stress markers in the liver tissue of mice with hepatic steatosis after treatment with GLP-1 analogs. Activation of GLP-1 receptors activates protein kinase $\mathrm{A}(\mathrm{PKA})$ and increases the production of cAMP via increasing intracellular $\mathrm{Ca}^{2+}$ and stimulation of adenylate cyclase enzyme. ${ }^{[34]}$ Both PKA and cAMP are inhibitors of NOX and, accordingly, ROS production. ${ }^{[35]}$ However, the role of GLP-1 varies in different cell types and has to be investigated depending on various factors, such as stimuli, species and the expression of the GLP-1R.

Finally, in this study, the histopathological evaluation of liver tissues showed loss of architecture, hepatocytes ballooning, macro- and microvesicular steatosis, inflammation, apoptotic nuclei, occasional binucleation, cellular inflammatory infiltrate and bridging fibrosis and pericellular fibrotic changes in steatohepatitis placebo-treated group. These changes were remarkably improved in the liraglutide-treated group than the sitagliptin-treated group. Liraglutide decreased hepatocyte ballooning, steatosis, inflammation, although not reaching statistical significance in comparison with sitagliptin. Bridging fibrosis was observed in most in the steatohepatitis placebo-treated group and was not significantly affected by treatments. Portal inflammation was not significantly different among liraglutide-treated and sitagliptin-treated groups, although a nominal reduction was observed by treatment with liraglutide.

\section{CONCLUSION}

Treatment with either GLP-1 RAs or DPP-IV inhibitors improved the hepatocyte viability by inhibiting its inflammation, improving the hepatic fatty deposition and attenuating the progression of hepatic fibrosis. These drugs also correct resulting dyslipidemia, histopathological changes and reduced the hepatic oxidative stress in male steatohepatitis rats, with slightly superior effects for GLP-1 RAs.

\section{ACKNOWLEDGEMENT}

This work was supported by the Deanship of Scientific Research, Taif University, Saudi Arabia and the authors extend their profound gratitude to them.

\section{CONFLICT OF INTEREST}

The authors declare that they have no known competing financial interests or personal relationships that could have appeared to influence the work reported in this paper.

\section{ABBREVIATIONS}

GLP-1 RAs: Glucagon-like peptide-1 receptor agonists; DPP-IV: Dipeptidyl peptidase-IV; NO: Nitric oxide; MDA: Malondialdehyde; NASH: Non-alcoholic steatohepatitis; HFD: High-fat diet; NG: Normal control group; SPG: Steatohepatitis placebo-treated group; SLG: Steatohepatitis liraglutide-treated group; SSG: Steatohepatitis sitagliptin-treated group; GSH: Reduced glutathione; CAT: Catalase; GPx: Glutathione peroxidase; SOD: Superoxide dismutase; TAC: Total antioxidant capacity; PKA: Protein kinase A.

\section{REFERENCES}

1. Piacentini M, Baiocchini A, DelNonno F, Melino G, Barlev NA, Rossin F, et al. Non-alcoholic fatty liver disease severity is modulated by transglutaminase type 2. Cell Death Dis. 2018;9:257.

2. Cho YM, Fujita Y, Kieffer TJ. Glucagon-like peptide-1: Glucose homeostasis and beyond. Annu Rev Physiol. 2014;76:535-59.

3. Yoon SH, Hee-Sook J. Effects of Glucagon-Like Peptide-1 on Oxidative Stress and Nrf2 Signaling. Int J Mol Sci. 2018;19(1):26.

4. Ahren B, Schmitz O. GLP-1 receptor agonists and DPP-4 inhibitors in the treatment of type 2 diabetes. Horm Metab Res. 2004;36(11/12):867-76.

5. Bourdel-Marchasson I, Schweizer A, Dejager S. Incretin therapies in the management of elderly patients with type 2 diabetes mellitus. Hosp Pract. 2011;39(1):7-21.

6. Dhir G, Cusi K. Glucagon like peptide-1 receptor agonists for the management of obesity and non-alcoholic fatty liver disease: A novel therapeutic option. J Investig Med. 2018;66(1):7-10.

7. Zhou GD1, Li MR, Zhang J, Pan D, Zhao SX, Yang JF, et al. Chitosan ameliorates the severity of steatohepatitis induced by high fat diet in rats. Scand J Gastroenterol. 2008;43(11):1371-7.

8. Hansen G, Jelsing J, Vrang N. Effects of liraglutide and sibutramine on food intake, palatability, body weight and glucose tolerance in the gubra DIO-rats. Acta Pharmacol Sin. 2012;33(2):194-200.

9. Onoyama T, Koda M, Okamoto T, Kishina M, Matono T, Sugihara T, et al. Therapeutic effects of the dipeptidyl peptidase-IV inhibitor, sitagliptin, on non-alcoholic steatohepatitis in FLS-ob/ob male mice. Mol Med Rep. 2015;12(5):6895-902.

10. Ellman M. A spectrophotometric method for determination of reduced glutathione in tissues. Anal Biochem. 1959;74(1):214-26.

11. Ali TM, Mehanna OM, Elsaid AG, Askary AE. Effect of Combination of Angiotensin-Converting Enzyme Inhibitors and Vitamin D Receptor Activators on Cardiac Oxidative Stress in Diabetic Rats. Am J Med Sci. 2016;352(2):208-14

12. Mehanna OM, EIAskary A, Al-Shehri S, El-Esawy B. Effect of phosphodiesterase inhibitors on renal functions and oxidant/antioxidant parameters in streptozocininduced diabetic rats. Arch Physiol Biochem. 2018;124(5):424-9.

13. Husain K, Suarez E, Isidro A, Ferder L. Effects of paricalcitol and enalapril on atherosclerotic injury in mouse aortas. Am J Nephrol. 2010;32(4):296-304.

14. Jamshidzadeh A, Baghban M, Azarpira N, Bardbori A, Niknahad H. Effects of tomato extract on oxidative stress induced toxicity in different organs of rats. Food and Chemical Toxicology. 2008;46(12):3612-5.

15. Lee J, Hong SW, Chae SW, Kim DH, Choi JH, Bae JC, et al. Exendin-4 improves steatohepatitis by increasing Sirt1 expression in high-fat diet-induced obese C57BL/6J mice. PLoS One. 2012;7(2):e31394.

16. Tushuizen ME, Bunck MC, Pouwels PJ, Waesberghe JHV, Diamant M, Heine RJ. Incretin mimetics as a novel therapeutic option for hepatic steatosis. Liver Int. 2006;26(8):1015-7.

17. Lee J, Hong SW, Rhee EJ, Lee WY. GLP-1 Receptor Agonist and Non-Alcoholic Fatty Liver Disease. Diabetes Metab J. 2012;36(4):262-7.

18. Jung YA, Choi YK, Jung GS, Seo HY, Kim HS, Jang BK, et al. Sitagliptin attenuates methionine/choline-deficient diet-induced steatohepatitis. Diabetes Res Clin Pract. 2014;105(1):47-57

19. Onoyama T, Koda M, Okamoto T, Kishina M, Matono T, Sugihara T. Therapeutic effects of the dipeptidyl peptidase-IV inhibitor, sitagliptin, on non-alcoholic steatohepatitis in FLS-ob/ob male mice. 2015;12(5):6895-902.

20. Lee YS, Shin S, Shigihara T, Hahm E, Liu MJ, Han J. Glucagon-like peptide-1 gene therapy in obese diabetic mice results in long-term cure of diabetes by improving insulin sensitivity and reducing hepatic gluconeogenesis. Diabetes. 2007;56(6):1671-9.

21. Zheng D, lonut V, Mooradian V, Stefanovski D, Bergman RN. Exenatide sensitizes insulin-mediated whole-body glucose disposal and promotes uptake of exogenous glucose by the liver. Diabetes. 2009;58(2):352-9.

22. Park S, Hong SM, Ahn IS. Exendin-4 and exercise improve hepatic glucose homeostasis by promoting insulin signaling in diabetic rats. Metabolism. 2010;59(1):123-33.

23. Tessari $P$, Coracina $A$, Cosma A, Tiengo A. Hepatic lipid metabolism and non-alcoholic fatty liver disease. Nutr Metab Cardiovasc Dis. 2009;19(4):291-302.

24. Sun F, Wu S, Wang J, Guo S, Chai S, Yang Z. Effect of glucagon-like peptide-1 receptor agonists on lipid profiles among type 2 diabetes: A systematic review and network meta-analysis. Clin Ther. 2015;37(1):225-41.

25. Scott R, Loeys T, Davies MJ, Engel SS. Sitagliptin Study 801 Group: Efficacy and safety of sitagliptin when added to ongoing metformin therapy in patients with type 2 diabetes. Diabetes Obes Metab. 2008;10(10):959-69.

26. Shirakawa J, Fujii H, Ohnuma K, Sato K, Ito $Y$, Kaji M. Diet-induced adipose tissue inflammation and liver steatosis are prevented by DPP-4 inhibition in diabetic mice. Diabetes. 2011;60(4):1246-57.

27. Schirra J, Nicolaus $M$, Roggel $R$, Katschinski M, Storr M, Woerle H. Endogenous glucagon-like peptide-1 controls the endocrine pancreatic secretion and antro-pyloro-duodenal motility in humans. Gut. 2006;55(2):148-50.

28. Qin X, Shen H, Liu M, Yang Q, Sabo M, Tso P. GLP-1 reduces intestinal lymph flow, triglyceride absorption and apolipoprotein production in rats. Am J 
Physiol Gastrointest Liver Physiol. 2005;288(5):G943-9.

29. Farr S, Taher J, Adeli K. Cardiovasc Hematol Disord Drug Targets. GLP-1 as a key regulator of lipid and lipoprotein metabolism in fasting and postprandial states. Cardiovasc Hematol Disord Drug Targets. 2014;14(2):126-36.

30. Meier J, Gethmann A, Gotze O, Gallwitz B, Holst J, Schmidt E. Glucagon-like peptide- 1 abolishes the postprandial rise in triglycerides concentrations and lowers levels of non-esterified fatty acids in humans. Diabetologia. 2006;49(3):452-8.

31. Li AN, Li S, Zhang YJ, Xu XR, Chen YM, Li HB. Resources and biological activities of natural polyphenols. Nutrients. 2014;6(12):6020-47.
32. Allam MM, EIGazzar WB. Exendin-4, a glucagon-like peptide-1 receptor agonist downregulates hepatic receptor for advanced glycation end products in non-alcoholic steatohepatitis rat model. Arch Physiol Biochem. 2018;124(1):10-7.

33. Ding X, Saxena NK, Lin S, Gupta NA, Anania FA. Exendin-4, a glucagon-like protein-1 (GLP-1) receptor agonist, reverses hepatic steatosis in ob/ob mice. Hepatology. 2006;43(1):173-81.

34. Baggio LL, Drucker DJ. Biology of Incretins: GLP-1 and GIP. Gastroenterology 2007;132(6):2131-57.

35. Kim JS, Diebold BA, Babior BM, Knaus UG, Bokoch GM. Regulation of Nox1 activity via protein kinase A-mediated phosphorylation of NoxA1 and 14-3-3 binding. J Biol Chem. 2007;282(48):34787-800.

Cite this article: Mehanna OM, Askary AAEE, Esawy BHE, Ali TM, Abo-Salem OM. Effects of Glucagon-like Peptide-1 Analogues and Dipeptidyl Peptidase-IV Inhibitors on Hepatic Oxidative Stress and Non-Alcoholic Steatohepatitis in Male Albino Rats. Int J Clin Exp Physiol. 2020;7(1):27-32. 